\title{
Response to: "Caring for the person with cancer and the role of digital technology in supporting carers"
}

\author{
Kohei Kajiwara ${ }^{1}$ (D) Jun Kako ${ }^{1} \cdot$ Mika Miyashita $^{1}$ \\ Received: 10 May 2019 / Accepted: 11 July 2019 / Published online: 18 July 2019 \\ (C) Springer-Verlag GmbH Germany, part of Springer Nature 2019
}

\section{Dear Editor:}

We read with interest the recent paper entitled "Caring for the person with cancer and the role of digital technology in supporting carers" by Heynsbergh et al. [1]. The authors concluded that digital technology may supply an opportunity to deliver support to carers of persons with cancer.

The usage of new technology by carers is an important area of future research. Previous research in caregiving reported the effectiveness of multi-component intervention, using computers and the World Wide Web [2]. Another previous study suggested the use of computer-mediated intervention for informal carers of persons with dementia [3]. We think that carers of persons with cancer could also benefit from such intervention. Previous studies of caregivers to lung cancer patients demonstrated that the comprehensive health enhancement support system can improve a caregiver's understanding, carers' appraisal, and problem-focused coping strategies [4, 5]. Furthermore, the possibility of maintaining the health of carers using wearable devices has also been suggested [6], and such support using devices is considered useful for caregivers of persons with cancer.

As the authors point out, the lack of background information about the characteristics and health status of the carers can be a major limitation. Based on our clinical experiences, the caregiving status of carers is important. In addition, recent research in the area of caregiving emphasized that formal support decreased unmet needs in caregivers of persons with dementia and affected caregiving satisfaction [7]. Therefore, we suggest that evaluating more detailed information about a carer's situation will provide more beneficial results.

Kohei Kajiwara

kkaji@hiroshima-u.ac.jp

1 Division of Nursing Science, Graduate School of Biomedical and Health Sciences, Hiroshima University, 1-2-3, Kasumi, Minami-ku, Hiroshima 734-8553, Japan
Undoubtedly, it is important to focus on support that can be offered to carers using technology. The study conducted by Heynsbergh et al. provided useful data in this regard. We believe that technology usage will be beneficial for caregivers of persons with cancer in the future.

\section{Compliance with ethical standards}

Conflict of interest The authors declare that they have no conflict of interest.

\section{References}

1. Heynsbergh N, Botti M, Heckel L, Livingston PM (2019) Caring for the person with cancer and the role of digital technology in supporting carers. Support Care Cancer 27(6):2203-2209

2. Wasilewski MB, Stinson JN, Cameron JI (2017) Web-based health interventions for family caregivers of elderly individuals: a scoping review. Int J Med Inform 103:109-138

3. McKechnie V, Barker C, Stott J (2014) Effectiveness of computermediated interventions for informal carers of people with dementia-a systematic review. Int Psychogeriatr 26(10):1619-1637

4. Namkoong K, DuBenske LL, Shaw BR et al (2012) Creating a bond between caregivers online: effect on caregivers' coping strategies. J Health Commun 17(2):125-140

5. DuBenske LL, Gustafson DH, Namkoong K et al (2014) CHESS improves cancer caregivers' burden and mood: results of an eHealth RCT. Health Psychol 33(10):1261-1272

6. Kajiwara K, Mantani A, Noto H, Miyashita M (2019) The relationship between caregiver burden and caregiver pulse rate measured by using a wristwatch-type pulsimeter with accelerometer in homebased family caregivers for persons with dementia: pilot study. Psychogeriatrics 19(1):83-84

7. Park M, Choi S, Lee SJ, Kim SH, Kim J, Go Y, Lee DY (2018) The roles of unmet needs and formal support in the caregiving satisfaction and caregiving burden of family caregivers for persons with dementia. Int Psychogeriatr 30(4):557-567

Publisher's note Springer Nature remains neutral with regard to jurisdictional claims in published maps and institutional affiliations. 